\title{
Mitigating Inequalities In Community Care Needs Of Older Adults With Dementia: An Integrated Model Of Community Care Operated Under The Proportionate Universalism Principle
}

\author{
Siu-Ming Chan \\ Shatin, N.T. Hong Kong \\ Gary Ka-Ki Chung \\ Shatin, N.T. Hong Kong \\ Michelle Ho-Wing Kwan \\ The Chinese University of Hong Kong \\ Jean Woo ( $\sim$ jeanwoowong@cuhk.edu.hk) \\ Shatin, N.T. Hong Kong
}

\section{Research Article}

Keywords: Integrated care, Voucher, Equity, Public-private partnership

Posted Date: February 14th, 2022

DOI: https://doi.org/10.21203/rs.3.rs-1337707/v1

License: (c) (i) This work is licensed under a Creative Commons Attribution 4.0 International License. Read Full License 


\section{Abstract}

Background: With reference to the medico-social integrated day care model of the Cadenza Hub for older people with dementia, we examined whether services subsidized by the publicly funded graded financial support of the Community Care Service Voucher for the Elderly (CCSV) could mitigate social inequalities in community care needs of older adults and their caregivers.

Methods: Semi-structured individual interviews with 14 caregivers of active day care service users with dementia were conducted between June and August 2021. The transcribed data were closely read to capture key themes using thematic analyses.

Results: The emerged themes included (i) Tremendous caregiving burden in the absence of community care support; (ii) Struggle in choosing care services; (iii) Benefits of the day care service; (iv) Financial support to ensure equitable access to community care; and (v) The role of NGO and social worker in bridging the information gap.

Conclusions: The integrated day care of the Cadenza Hub appeared to have addressed the unmet needs of older adults with dementia and their caregivers, including the socioeconomically disadvantaged with the CCSV support.

\section{Introduction}

Population ageing is a challenging societal and public health issue, especially in developed Asian regions like Hong Kong. Over the recent decades, promoting healthy ageing in the community has gained increasing research and policy attention over and above simply prolonging life or preventing diseases given the longest life expectancy across the globe. As highlighted by the World report on ageing and health of the World Health Organization, the health status of older adults may not be measured solely by the occurrence of chronic diseases, disabilities, and life expectancy, but also by alternative measures of healthy ageing which emphasizes both physical and cognitive functions (1).

In this connection, the documentation of geriatric syndromes (as opposed to diseases) which reflect the ageing process itself (2) and their social determinants will be important. These may be grouped into personal factors such as lifestyle, socioeconomic, and psychosocial factors, and environmental factors that include both the physical and social environment (3). Moreover, there is ample evidence of social inequalities in health among older people in Hong Kong, where a social gradient exists in declines of cognitive and physical function, in depression, in avoidable hospital admissions, and in healthy life expectancy (4-11). Geographic variations in health outcomes are also commonly observed across districts, which may have been shaped by both the physical and social environment. A significant contributor to these inequalities is ageism, a prominent phenomenon in Hong Kong (12) which results in neglect of policies directed to the design and provision of services targeted to needs, slow development of a community continuing care system that is fit-for-purpose (13), as well as inadequate training of health and social care professionals at all levels of care for older adults. Currently in the community, there is extensive unmet needs (13) and increasing caregiving stress $(14,15)$.

In many developed economies in Asia which have been experiencing population ageing, there is a move towards medicosocial integration care models in the community that covers preventive as well as needs-based long term care, financed by long term care insurance (16). Nonetheless, in Hong Kong, such services are either rudimentary, unaffordable, or of low quality and not targeted towards preserving or optimizing function. As the primary care services are largely private with substantial out-of-pocket charges, for many older adults who cannot afford this the first point of contact of care is the Accident and Emergency Department of public hospitals since this service is free or at low cost. In the absence of long-term care insurance or mandatory healthcare insurance, the Hong Kong government has recently launched a means-tested Pilot Scheme on Community Care Service Voucher for the Elderly (CCSV) with different levels of co- 
payment (17). Following the "affordable users pay" principle, older adults are required to pay at the rate of $5 \%, 8 \%, 12 \%$, $16 \%, 25 \%$, or $40 \%$ of the community care service package value of voucher depending on family household income but not asset, while the Hong Kong government pay for the rest of package value (17). Therefore, the CCSV scheme may provide different levels of safety net for community-dwelling older adults in need across the social ladder.

With the graded financial support by the Government, the existing inequalities in community care needs in Hong Kong could possibly be addressed if effective community care services are also in place. One exemplary community service is the Cadenza Hub, a novel medio-social integrated model of community care for older adults in Hong Kong. It is a community service project initiated and funded by The Hong Kong Jockey Club Charities Trust in 2009 in response to the challenges of population aging $(18,19)$, which aims at promoting an age-friendly community and improving the quality to life of older adults as well as their caregivers in Hong Kong (20). Currently, the day care service of the Cadenza Hub is largely targeted at older adults with dementia. Hence, given the potential equity impact of this public-private partnership in providing medico-social integrated day care in the Cadenza Hub, the present study aimed to examine whether this service model is effective in mitigating social inequalities in community care needs of older adults and their caregivers.

\section{Research Methods}

\section{Study population}

This study adopted a purposeful sampling method to recruit caregivers or close relatives of active users of the Cadenza Hub via referrals by the Hub manager. As the users with dementia were not capable of answering questions in detail due to cognitive limitations, this sampling approach enabled an in-depth investigation into the day care service experience from the perspective of their caregivers, as well as the subjective feeling and views of the caregivers themselves. To maximize the variation of sample, 14 caregivers with varying socioeconomic position, family background, and duration of day care service utilization were recruited for individual interviews.

\section{Data collection}

Participants were interviewed by two trained researchers between June and August 2021. A semi-structured interview guide was developed with reference to the existing literature related to community care, gerontology, and social services. Participants were also invited to openly share their views on the service of the Cadenza Hub and the community care in Hong Kong. All the participants filled a fact sheet about their socioeconomic position and family background. The interviews were conducted in Cantonese for around 45 to 60 minutes each, which were audio-recorded with the consents of participants.

\section{Background of participants}

Among the 14 participants, all of them are caregivers of the Cadenza Hub users diagnosed with mild, moderate, or severe levels of dementia. Their duration of day care service utilization ranged from 2 months to more than 6 years. Regarding the caregivers, nine of them were female and five were male. In terms of employment status, four of them were working full-time or part-time, three were housewives, and seven were retired. All of them used CCSV with varying co-payment levels ranging from level I to level IV. For further background information of the participants please refer to Table 1.

\section{Data analysis}

The interview data were transcribed into Chinese texts by trained student helpers and checked by the interviewers before analysis. Thematic analysis strategy was applied following the suggestions of Braun and Clarke (21), including familiarizing the data, generating initial codes, searching for themes, reviewing the themes, defining and naming the 
themes, and producing the report. Three researchers read and re-read the transcripts, and the data were coded and further formulated into meaningful themes. The quoted transcripts and formulated coding were translated into English by bilingual researchers. The data analysis put special attention to the experience of caregiving, use of day care service, and opinions on the community care.

\section{Ethical considerations}

All participants signed the written informed consent forms. The participation in the interviews was voluntary, and participants could withdraw from the interviews at any time. All the audio-recorded interviews and transcripts were kept strictly confidential for research purpose only.

\section{Results}

\section{Theme 1: Tremendous caregiving burden in the absence of community care support}

Taking care of older adults with dementia was a huge challenge for caregivers. Many caregivers expressed their sorrow and frustration during the interviews, as they did not have any professional knowledge in dementia and had no training on caregiving before using the Cadenza Hub service. They were at a loss when taking up the caregiving role all of a sudden, and needed to put a lot of time and effort on caregiving by giving up their own social life.

'When I started to be a caregiver, I was incompetent, I didn't know how to care for my mother. I felt devastated. One time, my mum was at the hospital and my brother got a stroke. My brother had gone crazy, both of them. I was so helpless at that time... No one can help me out. My brother's wife was in Mainland China, she didn't come to Hong Kong to help. I had to take care of everything by myself, for both of them.... Luckily, I have some good neighbours to help me out during difficult times. My relatives and friends do not live nearby, it is hard to ask them to come and help without a strong reason. Fortunately, here (Cadenza Hub) had a dementia assessment for my mum to do to find out what causes her abnormal behaviour, then I realised it is because of dementia.' (Case 3, female, 53)

I was devastated at that time, after my mother being discharged from the hospital, I had no idea what to do when we were home. She could not take care of herself. We didn't let her sleep in her room, we placed her in the living room to look after her more easily... Being a caretaker is tied up with responsibilities, I need to make priorities...our main focus is to take care of her, no other things can go above this priority. For example, I rarely hang out with my friends, luckily my friends are considerate and willing to accommodate my needs when scheduling the time to meet. I can still hang out with friends no matter when and where I am, not reduce to none, but still... it has reduced a lot. (Case 8, female, 62)

\section{Theme 2: Struggle in choosing care services}

Choosing appropriate care services for older adults was a common challenge for all caregivers. While possible options include applying for residential care homes, employing foreign domestic helpers, visiting community centres, or using community care services, caregivers tend to prefer community care services and put residential care homes as their last resort due to the less desirable environment.

Because my brother is living in aged care, I am more alert to the problems of the aged care services. I would feel heartbroken if I send my mother to stay at aged care. I would rather be hard on myself to take care of my mother than sending her to aged care. At that time, my mother was able to walk, or using a wheelchair... I didn't want to send her there... But I still put in an aged care application for her, it usually takes three to five years for a spot... I didn't want her to stay at aged care at all unless her health and functions decline significantly. I like to keep her out of aged care because she can do exercise in the daytime, where she can practice preventing memory loss. At aged care, the care workers don't care about the resident's activity level, they let the residents sleep all day, some residents pass away in a few months or 
not longer than a year. So, that's the reason why I prefer my mother to come here (Cadenza Hub) than staying at the aged care, so she can practice how to take care of herself. (Case 3 , female, 53)

Moreover, participants generally agreed that the environment as well as the services in the Cadenza Hub were much better than those of residential care homes.

I had visited a lot of elderly centres, including service centres. The Cadenza Hub is really clean, tidy, and new. I think the Cadenza Hub belongs to a first-class facility, probably. It is unbeatable. Whenever you go to other centres, you will find a great difference. (Case 1, male, 57)

There is no doubt that this day care centre is always our first choice. Although we are still queuing for the residential care homes for older adults as a backup plan when we can no longer take care of my sister, sending her to residential care homes is our last resort. (Case 9, male, 62)

Considering the current situation, I prefer the day care centre. It is because my husband and I can still take care of my mother. The day care service is a better choice for older adults as they are more familiar with the environment at home. Just like children would be reluctant to go and adapt to a new environment. (Case 14, female, 57)

Moreover, the Cadenza Hub provided social activities and training sessions to the users that could not be arranged by foreign domestic helpers. The professional services, such as physical muscle training and aroma massage therapy, available in the Cadenza Hub received positive feedback from many users.

My mum loves to come here (Cadenza Hub) because she didn't get to go to school when she was young. So, she is so glad to join the social activities here. Normally, she doesn't like to do exercise. After coming to the hub, she keeps doing exercise regularly. She became more energetic and healthier than before, and developed a regular lifestyle. Now, her condition is very well, I noticed that the oedema on her legs has improved after doing the aroma massage therapy. The therapist has done a very good job. My mum is happy to see her legs without oedema (Case 4, female, 64)

\section{Theme 3: Benefits of the day care service}

The significant improvement of physical ability and mental health of service users explained why they prefer to stay in the Cadenza Hub. Most of the caregivers felt hopeless when they knew their parents or relatives suffered from dementia, but the improvement of users gave them hope again. The training at least slowed down the deteriorating process of the older adults.

He has made a lot of improvements over this year. In the beginning, he had no contact with others. No eye contact, nothing. He won't care about anything when he got into the lift. Then he got better, he has started to say hi to people and took the initiative to greet people. And now, he even chats with others. The centre (Cadenza Hub) has made a lot of positive changes in his personality... The centre has changed him a lot by showing a great improvement in changing clothes and cleanliness. So, I believe the care provided at the centre is effective and helpful to him... His social skill is getting better and this emotion is also well stable, less likely to lose his temper. (Case 1, male, 57)

(What do you find helpful in the one-on-one exercise class?) We have learnt a set of skills, such as when she gets up to sit on a wheelchair... she has to hold on to the table to get up, then sits on the wheelchair behind her. There are some tips about it, which is to ask her to lean forward when getting up, it would be easier for her to hold on to the table without using much effort. We didn't know all this before taking the class. (Case 8, female, 62)

The day care centre helps a lot, we have pushed back the date of admitting to the elderly home. The Cadenza Hub is located near my home, we live upstairs. It provides cognitive training which I don't know how to train her myself. And the 
centre holds a variety of activities for her to learn and work on, which may help to maintain her condition and delay the degeneration. The services provided at the centre are more professional than what family can do, it should be helpful... (Case 12, male, 74)

The service provided by Cadenza Hub does not only enhance the well-being of the older adults, but also benefit the caregivers. As most caregivers bear huge pressure in taking care of their parents or relatives, the day care service gave them appropriate support and free time for their own commitment.

(Does the service provided by Cadenza Hub help in reducing your stress?) Yes, of course. Cadenza Hub takes care of her for a few hours, she can do some exercise, chatting with others... It would be nice to always be with her, but I have to work and sustain a living. There is a benefit to go to work, which I don't need to stick with her all day long. I don't think being with her is something I can't accept. I'd like to stay with her, but I have to go to work. She goes to Cadenza Hub 20 days per month. It is absolutely helpful, it must be helpful by all means. (Case 2, male, 60)

(Any changes after you joined the Cadenza Hub day care centre?) There is more time for me to relax. I can go out for my activities, or to relax for a few hours. And here (Cadenza Hub) has taught me a lot. For example, when I have difficulties I can't solve, the staff here would give me practical advice. For example, when my mother is unable to take a shower on her own, the staff would teach me how to hold my mother at the shower... with opening wounds, the staff would take a look at it and teach me how to manage it. Also, they would let me know when my mother doesn't eat well and give me suggestions. I am impressed with the details of caring at the centre. The staff are always welcome for questions. (Case 3 , female, 53)

\section{Theme 4: Financial support to ensure equitable access to community care}

As most existing community care services are privately funded with substantial out-of-pocket payment, many caregivers expressed that they would not have been able to afford the day care service in the absence of the financial support by CCSV.

'There is no doubt that the social service vouchers (CCSV) have helped me a lot. It is better to receive financial aid from the government. If not, we won't be able to join the Cadenza Hub or the day care centre. How can someone receiving the CSSA join the Cadenza Hub? It is affordable when it is subsidized with the service vouchers... We need to pay $5 \%$ of the fee only, around $\$ 300$ HKD per month... Without the voucher, it would be $\$ 500$ HKD per day. If paying the total fee out of my pocket, I won't be willing to spend that much, unless I am wealthy. It is my thoughts only, maybe others can afford it, but not me.' (Case 12, male, 74)

'We got the service vouchers (CCSV) unexpectedly, which can save some money for her to join the aroma massage therapy and one-on-one exercise in Cadenza Hub. Since my mum's health condition has improved, less money is being spent on other medical care.' (Case 4, female, 64)

'The service voucher (CCSV) helps a lot financially, it makes a big difference, the regular fee is more than ten-thousand dollars!... If I pay the regular price, I have to pay more than ten-thousand dollars a month, which is really expensive. Without the voucher, I will never join the Cadenza Hub. It is about $\$ 400$ HKD per day. Would a normal family pay $\$ 400$ HKD per day to take care of the elderly?' (Case 13, female, 62)

\section{Theme 5: The role of NGO and social worker in bridging the information gap}

Social workers and NGO played an important role in bridging the gap between the clients in need and the existing community service. Many caregivers had no ideas about community care services before getting in touch with social 
workers. The advertisements of community services may not reach the cases in need. Most of the service users applied for the service mainly by referral of social workers or workers in community centres.

We have seen many advertisements at the estate about the community services for the elderly. However, you won't know what it is if you never come close to check. The elderly won't notice there are services for them. They also don't get on to the internet. (Case 5, female, 45)

(How do you know about Cadenza Hub?) It is mainly recommended by the medical social worker. The social worker has introduced what sort of services are provided at the hub to me, which I find it suitable for my mother-in-law to join. Therefore, we have joined since then. (Case 6, female, 53)

When I was applying the service vouchers for my sister, the medical social worker helped me out. She did the assessment of our case, and we are eligible to get it, then she brought the vouchers to us. This social worker has helped me a lot. But I need to put in the efforts to attend the day care centre (Cadenza Hub) to find out the information and ask for assistance. At the end of the day, I still need to do part of the work to make it happen. In my opinion, the social worker isn't a one-off solution, you cannot expect things to be done by others or the staff only, you will need to work with them as well. (Case 9, male, 62)

\section{Discussion}

\section{Summary of findings}

The novel medico-social integrated day care model of the Cadenza Hub appeared to have addressed the unmet needs of older adults with dementia and their caregivers, including those of a relatively lower socioeconomic position with the support of the publicly funded CCSV scheme. Substantial improvement on the self-care, functionality, social skills, and psychosocial well-being of older adult users across different socioeconomic background has been observed, in addition to stress relief among caregivers. Despite limitations on service referral and delivery, the day care service has the potential to fill the gaps of existing services and thus retain older adults with dementia in the community as long as possible.

\section{Addressing the unmet community care needs via the day care model}

The day care model of the Cadenza Hub tackles the unmet community care needs through a series of inter-related support including a comprehensive geriatric assessment followed by multidisciplinary and person-centred management for both dementia-specific illnesses and more general health and psychosocial wellbeing, technological assistance and training for older adult users, proactive support for caregivers, as well as a comfortable setting that facilitates social interactions with other older adults and their caregivers $(18,19)$. The design of the day care model echoes with the 8 Pillars Model of Community Support developed by Alzheimer Scotland which emphasizes resilience building by providing the best possible health and social support to people with dementia to live in their local community (22). A recent systematic review also supported the concrete benefits of organizational-level patient and family-centred care on the quality of life of older adults with dementia (23). Hence, the day care model goes beyond rehabilitative programmes but primarily optimizes health and function of older adult users in terms of the physical, psychological, functional, nutritional, and social domains, and provides caregiving support to facilitate continuity care at home and in the community (20). As community care is often a priority over hospital and residential care, the day care service supports older adults with dementia who have already been discharged from hospitals but are still in need of care to stay in the community, so as to avoid frequent hospital readmissions or resorting to residential care home services where many users suffer from a loss of dignity while their caregivers may also feel guilty under the traditional culture of filial piety (24). Moreover, the day care centre provided skill training and social activities which cannot hardly substituted by 
hiring a foreign domestic helper. Therefore, it is believed that the one-stop day care service could address the fragmentation between the healthcare and residential care sectors, enabling older adults with dementia to stay in and readapt to the community for healthy ageing.

\section{Mitigating the inequalities in community care needs with the CCSV support}

In addition to the direct health and social benefits to older adult users and their caregivers, the day care service of the Cadenza Hub also has profound implications on mitigating the underlying social inequalities in community care needs. Specifically, it helps improve health equity when the day care service promoting healthy ageing in place works in synergy with the launch of CCSV as a graded subsidy scheme, which makes quality person-centred community care affordable to all. In contrast with many existing local social welfare schemes for low-income families that impose stringent and rigid eligibility criteria (25), the graded co-payment arrangement of the CCSV scheme is indeed in line with the approach of "proportionate universalism" proposed by Prof. Sir Michael Marmot in his first Strategic Review of Health Inequalities in England (26). On one hand, the scale of CCSV subsidy is proportionate to the level of socioeconomic disadvantage in terms of household income; on the other hand, the wealthiest group is not left behind but still entitled to financial support with a higher level of co-payment (i.e., $40 \%$ ). Hence, such a graded financial support to quality community care services ensures that health actions are universal to all but in proportion to socioeconomic and health needs. Furthermore, the financial support by CCSV has a wider equity and psychosocial impact on the disadvantaged caregivers of older adult users. With the day care service, they are temporarily relieved of the caregiving burden to focus on work in the daytime, which would otherwise not have been feasible without the CCSV support. They could also have the capacity to allocate their limited financial resources on basic necessities and health investment within their own families. Altogether, with the CCSV support, the disadvantaged caregivers could be lifted out of poverty or impoverishment due to caregiving and related health expenses, and thus stand a better chance of breaking the vicious cycle of poverty and ill-health (25).

Nonetheless, one potential barrier to achieving health equity lies in the accessibility to information regarding the existing community care services and social welfare schemes. Despite the aid of social workers for referrals, older adults and their caregivers often get frustrated if they are less competent and digitally literate to search for appropriate services and support on their own. This issue could be improved by a better integration and promotion of the diverse existing community care services, possibly disseminated via public outpatient clinics, government-led community elderly centres across districts, relevant non-government organizations for older adults, and housing estates. Further collaboration with community providers to offer digital training and support could also enable older adults and their caregivers to access online information and recognise the tools, products, services, and activities they need, so that they can take a more proactive approach to managing their health condition with less reliance on the healthcare system (27).

\section{Public health implications}

The public-private partnership approach to providing medico-social integration care in the community (i.e., private day care services of the Cadenza Hub supported by the publicly funded CCSV scheme in this study) is not only applicable to older adults with dementia but could be adopted more broadly as a community service delivery model to address other health issues and related inequalities. To better fill the service gap beyond expanding the capacity of services in the public sector, the government could also provide financial support to users and engage community service providers (e.g., private organizations, non-government organizations, and social enterprises) which have a greater flexibility to design innovative health and social services that effectively meet the community care needs of their target audience (28, 29). In addition, the public-private partnership is conducive to a stronger financial sustainability of community service providers by supporting part of their operational cost on human resources, technologies, and services (29). Additional 
incentives such as rent waiver may also further alleviate the cost constraints; thereby promoting a better quality of community care services.

\section{Limitations}

There are several caveats in this qualitative study. First, the relatively small number of purposefully sampled participants limited the generalizability of our findings. Caregivers who have a stronger opinion about the day care service were more likely to participate in our study, possibly leading to voluntary response bias. Second, we assessed the health impact of the day care service on older adult users with dementia based on the observations and perception by their caregivers. The first-hand experience and perceived impact of the users could not be verified due to their cognitive limitations. Third, the duration of day care service utilization varied significantly across users; new users and caregivers may have limited experience and thus focused only on the short-term impact of the service. Last, while the potential health equity impact of the medio-social integrated day care service with the CCSV support has been illustrated in this study, further quantitative research is warranted to provide empirical evidence on whether such as service model could effectively mitigate the existing social inequalities in community care needs in Hong Kong.

\section{Conclusion}

The medico-social integrated day care service of the Cadenza Hub, coupled with the financial support by the government which followed the principle of proportionate universalism, appeared to have not only facilitated an all-round improvement in older adults with dementia and their caregivers but also mitigated the underlying social inequalities in community care needs by ensuring need-based access to the person-centred services across the social ladder. Such a public-private partnership approach to providing medico-social integration care in the community has a potential, as a community service delivery model, to address other health issues and related inequalities.

\section{Declarations}

\section{Ethics approval and consent to participate}

The study was approved by the Survey and Behavioural Research Ethics Committee of the Chinese University of Hong Kong in February 2021 (Ref no. SBRE-20-384). Written informed consent has been obtained from each of the participants.

\section{Consent for publication}

Not applicable

\section{Availability of data and materials}

A de-identified version of these data will be made available upon request to researchers who wish to explore different components of equity and associations that we have yet to explore.

\section{Competing interests}

The authors declare no conflicts of interest.

\section{Funding}

None. 


\section{Authors' contributions}

SMC planned and carried out the focus groups; data analysis and writing. GC data analysis and writing of the manuscript. MK carried out the focus group and data analysis. JW created the idea, articulated the research question, facilitated the focus groups and manuscript writing. All authors read and approved the final manuscript.

\section{Acknowledgements}

Gary Ka-Ki Chung acknowledges the Research Grant Council for its support over his Postdoctoral Fellowship (Ref. No.: PDFS2122-4H02). We also acknowledge the Hong Kong Jockey Club Charities Trust for supporting the operation of the Cadenza Hub.

\section{Author details}

${ }^{1}$ CUHK Institute of Health Equity, The Chinese University of Hong Kong, Hong Kong SAR, China. ${ }^{2}$ Department of Social and Behavioural Sciences, City University of Hong Kong, Kowloon Tong, Hong Kong SAR, China. ${ }^{3}$ CUHK Institute of Ageing, The Chinese University of Hong Kong, Hong Kong SAR, China. ${ }^{4}$ Department of Medicine \& Therapeutics, Faculty of Medicine, The Chinese University of Hong Kong, Hong Kong SAR, China.

\section{References}

1. World Health Organisation. World report on ageing and health 2015 [Available from: https://www.who.int/publications/i/item/9789241565042.

2. Cheung JTK, Yu R, Wu Z, Wong SYS, Woo J. Geriatric syndromes, multimorbidity, and disability overlap and increase healthcare use among older Chinese. BMC Geriatr. 2018;18(1):147.

3. Chau PH, Wong M, Woo J. Living Environment. In: Woo J, editor. Aging in Hong Kong A Comparative Perspective. New York: Springer; 2013. p. 31-67.

4. Lai ETC, Yu R, Woo J. The Associations of Income, Education and Income Inequality and Subjective Well-Being among Elderly in Hong Kong-A Multilevel Analysis. Int J Env Res Pub He. 2020;17(4):1271.

5. Yu R, Tong C, Leung J, Woo J. Socioeconomic Inequalities in Frailty in Hong Kong, China: A 14-Year Longitudinal Cohort Study. Int J Environ Res Public Health. 2020;17(4):1301.

6. Yu R, Leung J, Lum CM, Auyeung TW, Lee JSW, Lee R, et al. A comparison of health expectancies over 10 years: implications for elderly service needs in Hong Kong. Int J Public Health. 2019;64(5):731-42.

7. Lin JS, Leung J, Yu B, Woo J, Kwok T, Lau KKL. Socioeconomic status as an effect modifier of the association between built environment and mortality in elderly Hong Kong Chinese: A latent profile analysis. Environ Res. $2021 ; 195$.

8. Lai ETC, Yu R, Woo J. Social gradient of self-rated health in older people-the moderating/mediating role of sense of community. Age Ageing. 2021;50(4):1283-9.

9. Woo J, Goggins W, Sham A, Ho SC. Social determinants of frailty. Gerontology. 2005;51(6):402-8.

10. Wong SY, Mercer SW, Woo J, Leung J. The influence of multi-morbidity and self-reported socio-economic standing on the prevalence of depression in an elderly Hong Kong population. BMC Public Health. 2008;8:119. 
11. Chau PH, Woo J, Chan KC, Weisz D, Gusmano MK. Avoidable mortality pattern in a Chinese population-Hong Kong, China. Eur J Public Health. 2011;21(2):215-20.

12. Mak B, Woo J, Bowling A, Wong F, Chau PH. Health care prioritization in ageing societies: influence of age, education, health literacy and culture. Health Policy. 2011;100(2-3):219-33.

13. Woo J. Designing Fit for Purpose Health and Social Services for Ageing Populations. Int J Environ Res Public Health. 2017;14(5):457.

14. Ho SC, Chan A, Woo J, Chong P, Sham A. Impact of caregiving on health and quality of life: a comparative population-based study of caregivers for elderly persons and noncaregivers. J Gerontol A Biol Sci Med Sci. 2009;64(8):873-9.

15. Wong SY, Wong CK, Chan FW, Chan PK, Ngai K, Mercer S, et al. Chronic psychosocial stress: does it modulate immunity to the influenza vaccine in Hong Kong Chinese elderly caregivers? Age (Dordr). 2013;35(4):1479-93.

16. Woo J. Healthcare for Older People in Asia. Age Ageing (in press).

17. Social Welfare Department. Third Phase of the Pilot Scheme on Community Care Service Voucher for the Elderly 2021 [Available from: https://www.swd.gov.hk/en/index/site_pubsvc/page_elderly/sub_csselderly/id_psccsv/.

18. Y. R, Chau PH, McGhee S, Cheung WL, Chan KC, Cheung SH, et al. Dementia Trends: Impact of the Ageing Population and Societal Implications for Hong Kong. Hong Kong: The Hong Kong Jockey Club; 2010.

19. Jockey Club Cadenza Hub. Day care centre for people with dementia 2021 [Available from: https://jcch.org.hk/.

20. Woo J, Yu R, Leung G, Chiu C, Hui A, Ho F. An Integrated Model of Community Care for Older Adults: Design, Feasibility and Evaluation of Impact and Sustainability. Aging Medicine and Healthcare (in press). 2021;12(3):105-13.

21. Braun V, Clarke V. Using thematic analysis in psychology. Qualitative Research in Psychology. 2006;3:77-101.

22. Alzheimer Scotland. Delivering Integrated Dementia Care: The 8 Pillars Model of Community Support. Edinburgh: Alzheimer Scotland; 2012.

23. Chenoweth L, Stein-Parbury J, Lapkin S, Wang A, Liu Z, Williams A. Effects of person-centered care at the organisational-level for people with dementia. A systematic review. PLoS One. 2019;14(2):e0212686.

24. Chan CLW, Ho AHY, Leung PPY, Chochinov HM, Neimeyer RA, Pang SMC, et al. The Blessings and the Curses of Filial Piety on Dignity at the End of Life: Lived Experience of Hong Kong Chinese Adult Children Caregivers. Journal of Ethnic \& Cultural Diversity in Social Work. 2012;21(4):277-96.

25. Chung GK, Dong D, Wong SY, Wong H, Chung RY. Perceived poverty and health, and their roles in the poverty-health vicious cycle: a qualitative study of major stakeholders in the healthcare setting in Hong Kong. Int J Equity Health. 2020;19(1):13.

26. Marmot M, Allen J, Goldblatt P, Boyce T, McNeish D, Grady M, et al. Fair society, healthy lives. London: University College London; 2010.

27. Lupton D. The digitally engaged patient: Self-monitoring and self-care in the digital health era. Social Theory \& Health. 2013;11(3):256-70. 
28. National Academies of Sciences E, and Medicine; Health and Medicine Division; Board on Global Health; Forum on Public-Private Partnerships for Global Health and Safety. Engaging the Private Sector and Developing Partnerships to Advance Health and the Sustainable Development Goals: Proceedings of a Workshop Series. Washington (DC): National Academies Press (US); 2017.

29. Roundtable on the Promotion of Health Equity and the Elimination of Health Disparities; Board on Population Health and Public Health Practice; Health and Medicine Division; National Academies of Sciences E. The Private Sector as a Catalyst for Health Equity and a Vibrant Economy: Proceedings of a Workshop. Washington (DC): National Academies Press (US); 2016.

\section{Table}

Table 1. Basic characteristics of participants

\begin{tabular}{|c|c|c|c|c|c|c|c|c|c|c|}
\hline $\begin{array}{l}\text { Case } \\
\text { No. }\end{array}$ & Sex & Age & $\begin{array}{l}\text { Marital } \\
\text { Status }\end{array}$ & Education & $\begin{array}{l}\text { Employment } \\
\text { Status }\end{array}$ & $\begin{array}{l}\text { CCSV } \\
\text { level }\end{array}$ & $\begin{array}{l}\text { Level of } \\
\text { Dementia }\end{array}$ & $\begin{array}{l}\text { Period } \\
\text { of Use } \\
\text { (in } \\
\text { months) }\end{array}$ & $\begin{array}{l}\text { Hired } \\
\text { Maid }\end{array}$ & $\begin{array}{l}\text { Living } \\
\text { with } \\
\text { user }\end{array}$ \\
\hline 01 & M & 57 & married & $\begin{array}{l}\text { senior high } \\
\text { school }\end{array}$ & retired & II & mild & 15 & no & no \\
\hline 02 & M & 60 & married & $\begin{array}{l}\text { junior high } \\
\text { school }\end{array}$ & $\begin{array}{l}\text { full time } \\
\text { employee }\end{array}$ & II & moderate & 45 & no & yes \\
\hline 03 & $\mathrm{~F}$ & 53 & single & $\begin{array}{l}\text { junior high } \\
\text { school }\end{array}$ & housewife & I & severe & 64 & no & yes \\
\hline 04 & $\mathrm{~F}$ & 64 & single & undergraduate & $\begin{array}{l}\text { full time } \\
\text { employee }\end{array}$ & II & mild & 18 & no & yes \\
\hline 05 & $\mathrm{~F}$ & 45 & married & undergraduate & $\begin{array}{l}\text { full time } \\
\text { employee }\end{array}$ & III & mild & 76 & no & no \\
\hline 06 & $\mathrm{~F}$ & 53 & married & $\begin{array}{l}\text { senior high } \\
\text { school }\end{array}$ & housewife & IV & severe & 61 & yes & no \\
\hline 07 & $M$ & 89 & married & $\begin{array}{l}\text { primary } \\
\text { school }\end{array}$ & retired & I & moderate & 20 & no & yes \\
\hline 08 & $\mathrm{~F}$ & 62 & single & $\begin{array}{l}\text { senior high } \\
\text { school }\end{array}$ & retired & II & severe & 36 & no & yes \\
\hline 09 & $M$ & 62 & married & undergraduate & retired & IV & moderate & 15 & yes & no \\
\hline 10 & $\mathrm{~F}$ & 73 & married & $\begin{array}{l}\text { junior high } \\
\text { school }\end{array}$ & retired & II & mild & 2 & no & yes \\
\hline 11 & $\mathrm{~F}$ & 74 & married & $\begin{array}{l}\text { primary } \\
\text { school }\end{array}$ & retired & III & mild & 24 & no & yes \\
\hline 12 & $M$ & 74 & married & $\begin{array}{l}\text { junior high } \\
\text { school }\end{array}$ & retired & I & moderate & 38 & no & yes \\
\hline 13 & $\mathrm{~F}$ & 62 & married & $\begin{array}{l}\text { primary } \\
\text { school }\end{array}$ & $\begin{array}{l}\text { part-time } \\
\text { employee }\end{array}$ & II & severe & 10 & no & yes \\
\hline 14 & $\mathrm{~F}$ & 57 & married & $\begin{array}{l}\text { senior high } \\
\text { school }\end{array}$ & housewife & II & moderate & 29 & no & yes \\
\hline
\end{tabular}

